Technological University Dublin

DÜBLIN

ARROW@TU Dublin

2005-01-01

\title{
Linear Electronic and Optical Processes in Fullerene Thin Films
}

Jonathan Moghal

Technological University Dublin, Jonathan.Moghal@tudublin.ie

Naomi Brant

Technological University Dublin, Naomi.Brant@tudublin.ie

Siobhan Phelan

Technological University Dublin

See next page for additional authors

Follow this and additional works at: https://arrow.tudublin.ie/radcon

Part of the Physics Commons

\section{Recommended Citation}

Moghal, J., Brant, N. \& Phelan, S.B. (2005). Linear electronic and optical processes in Fullerene thin films. Proceedings of Opto-Ireland, 2005. SPIE, vol. 5824, pg. 33. doi:10.1117/12.605177

This Conference Paper is brought to you for free and open access by the Radiation and Environmental Science Centre at ARROW@TU Dublin. It has been accepted for inclusion in Conference papers by an authorized administrator of ARROW@TU Dublin. For more information, please contact arrow.admin@tudublin.ie, aisling.coyne@tudublin.ie,gerard.connolly@tudublin.ie. 
Authors

Jonathan Moghal, Naomi Brant, Siobhan Phelan, Hugh J. Byrne, and Gordon Chambers

This conference paper is available at ARROW@TU Dublin: https://arrow.tudublin.ie/radcon/7 


\title{
Linear electronic and optical processes in Fullerene thin films
}

\author{
J. Moghal*, N. Brant, S.B. Phelan, H.J. Byrne, G. Chambers \\ Focas Institute/School of Physics, Dublin Institute of Technology, Kevin Street, Dublin 8, \\ Ireland.
}

\begin{abstract}
The electrical properties of $\mathrm{C}_{60}$ have been extensively studied in both the solid and solution phases. The vibrational spectroscopy of $\mathrm{C}_{60}$ is predominantly molecular in character. However electronic spectroscopy reveals features, which are specific to the solid. These features have been attributed to intermolecular charge transfer states. The relative importance of these inter - and intramolecular processes in terms of their contribution to the electronic transport is discussed. Cyclic voltammetry is employed to generate charged molecular species, which also contribute to the conduction process and comparisons to optical excited states species are drawn. The cyclic voltammetry was monitored in situ with vibrational spectroscopy so as to observe any shifts in the $\mathrm{C}_{60}$ spectrum due to charging. The current voltage characteristics of thin film sandwich structures fabricated by vacuum are then presented and discussed. A strongly non-linear behaviour is observed, a sharp increase in the device conductance being observed at relatively low voltages at both room temperature and at $20 \mathrm{~K}$. The room temperature IV curves confirm a lattice collapse upon charging. The high conductivity state is however observed to be stable at low temperature.
\end{abstract}

Keywords: $\mathrm{C}_{60}$, Electronic Properties, Cyclic Voltammetry, Raman, IV characteristics

\section{INTRODUCTION}

Fullerene science has been proposed to hold great promise for nanotechnology. Indeed the potential of $\mathrm{C}_{60}$ is well renowned. In the past few years fullerenes, namely $\mathrm{C}_{60}$, and its derivatives have been subjected to intense research for a wide range of potential applications in the science industry. The discovery of Buckminsterfullerene $\left(\mathrm{C}_{60}\right)[1]$ triggered an explosion of research in the early 90's, which gave birth to fullerene science.

This work primarily focuses on the arch-type fullerene, which is $\mathrm{C}_{60} . \mathrm{C}_{60}$ is electron rich, and yet can be six fold reduced, taking on up to six additional electrons [2]. Interest in electrical properties of the solid were intensified when it was observed that they could be chemically doped with alkali metals, producing a metallic state $\mathrm{A}_{1} \mathrm{C}_{60}$, and even a superconducting state $\mathrm{A}_{3} \mathrm{C}_{60}$ [2]. This corresponds to a transfer of 1 and 3 electrons to the LUMO state of each $\mathrm{C}_{60}$ molecule respectively. The LUMO of the $\mathrm{A}_{6} \mathrm{C}_{60}$ salt is completely full, and the material is electrically insulating. It has been shown that a similar partial occupation of the LUMO band can be achieved by optical pumping of the $\mathrm{C}_{60}$ solid, and at a critical excitation density, an insulator to metal transition is observed [3]. A reversible insulator to metal transition has great potential for device applications, however the requirement for optical pumping is impractical. As a result of this a number of groups have concentrated their studies towards electronically inducing the reversible insulator to metal transition, the most high profile being the controversial work reported by Jan Hendrik Schön [4]. Schön and his colleagues at Bell Labs wondered whether instead of converting insulating $\mathrm{C}_{60}$ into a superconductor by doping it with potassium atoms, they could use the electric fields produced by an FET geometry to induce a conducting channel in $\mathrm{C}_{60}$. If the density of charges were high enough, perhaps the material would resemble a metal like copper, or maybe even a superconductor. This was not a simple condition to achieve; the density of free electrons in a metal is at least 1000 times greater than that of a semiconductor and if a high electron concentration is required a very high field must be applied to the gate electrode. This was virtually impossible as the FET would be turned to ash but somehow over his experiments, Schön proclaimed that he had succeeded in getting this to work. Unfortunately though no one else was able to reproduce the work of Schön [5].

Other groups have reported changes in the conductivity of single crystals of $\mathrm{C}_{60}$ and of fullerene thin films [6] where it was noted that the conductivity of the films jumps by an order of six in magnitude and was also seen to be stable at low temperatures. 
Indeed Smie and Heinz reported that the point that the $\mathrm{C}_{60}$ film was most conducting was equivalent to the first reduction peak obtained for a film using cyclic voltammetry. They showed that solid-state measurements of $\mathrm{C}_{60}$ at room temperature showed that the $\mathrm{C}_{60}$ could be charged up to its di-ionic state in two separated potential steps [7]. In this paper the electrical generation of ionic species, which could potentially contribute to the electronic transport in solid-state $\mathrm{C}_{60}$, is examined using cyclic voltammetry techniques. The current voltage characteristics of thin film sandwich structures fabricated by vacuum deposition of $\mathrm{C}_{60}$ on ITO with an aluminum top electrode are also presented in terms of solid-state voltammetric processes. Both are monitored in situ with vibrational spectroscopy.

\section{EXPERIMENTAL}

For the cyclic voltammetry of $\mathrm{C}_{60}$ films, $\mathrm{C}_{60}$ was deposited onto the surface of a $2 \mathrm{~mm}$ diameter Platinum electrode. Initially the electrode surface was polished, rinsed with relevant solvent and dried. The $\mathrm{C}_{60}$ in toluene was drop cast onto the electrode surface. The toluene was allowed to evaporate, and a $\mathrm{C}_{60}$ film was formed at the centre of the electrode. The electrolyte that was used was acetonitrile and the supporting electrolyte was $0.1 \mathrm{M}$ of Tetrabutylammonium Perchlorate (TBABF4). The electrochemical cell was then used in situ with Raman spectroscopy, so as to obtain Raman spectra at the reduction peaks of the $\mathrm{C}_{60}$ films.

$\mathrm{C}_{60}$ thin films were produced through vacuum sublimation of $\mathrm{C}_{60}$ powder onto glass predeposited with an indium tin oxide (ITO) layer. A small part of the ITO was etched away using boiling HCL exposing the glass. The substrates were then mounted into an Edwards Auto-305 evaporator, which was pumped down to a pressure of $10^{-6} \mathrm{mbar}$. The $\mathrm{C}_{60}$ was sublimed onto the ITO by resistively heating a molybdenum boat containing $\mathrm{C}_{60}$ powder. A layer of aluminum was deposited on top of the $\mathrm{C}_{60}$ to form the top electrode. The sandwich structures were electrically contacted in a cryostat and the current voltage measurements were recorded with a Keithley 237 programmable electrometer where the voltage was varied while measuring the current.

\section{RESULTS}

Figure 1shows the low voltage region of the current-voltage (IV) characteristic of a $\mathrm{C}_{60}$ film at room temperature. The IV is initially Ohmic with a conductivity of $\sim 6.0 \times 10^{-8} \mathrm{Scm}^{-1}$, determined from the slope from the beginning of the graph of $2.9 \times 10^{-4} \mathrm{~A} / \mathrm{V}$, film thickness of $1.0 \times 10^{-4} \mathrm{~cm}$, and film area of $0.48 \mathrm{~cm}^{2}$. As the voltage is increased the conductivity decreases to $3.5 \times 10^{-8} \mathrm{Scm}^{-1}$ determined from the second half of the graph with a slope of $1.7 \times 10^{-4} \mathrm{~A} / \mathrm{V}$. The change in conductivity is potentially due to space charge limited transport. Values for conductivity measurements of $10^{-10} \mathrm{Scm}^{-1}$ for pristine $\mathrm{C}_{60}$ films have been previously reported [8]. The lower conductivity of these films may be due to fact that they were measured in a planar geometry where conductivity is limited by polycrystalline domain boundaries. The sandwich geometry $\mathrm{C}_{60}$ film shows an insulating behaviour of low conductivity at low voltages and a temperature dependence study was carried out to investigate this behaviour. The results of this study are shown in figure 2 .

The temperature dependence of conductivity was performed by subjecting the $\mathrm{C}_{60}$ sample to $1 \mathrm{~V}$, holding it at this voltage and noting the current as the temperature was decreased from $293 \mathrm{~K}$ to $78 \mathrm{~K}$. If the samples were in an insulating state it would be expected that the current would decrease as the temperature was decreased, at these low voltages. Normal behaviour of a molecular insulator is thermally activated hopping. Figure 2 shows a decrease in current as the temperature is decreased as expected, however interestingly the rate of decrease of the current changes abruptly as it goes through the phase transition temperature. The activation energy above the transition temperature is very much higher than below. This implies that the intermolecular hopping energy is significantly increased above the transition temperature. This is consistent with decreased intermolecular mobility due to rotational motion [8].

The electrochemistry behavior of a $\mathrm{C}_{60}$ solution is totally different to that of a $\mathrm{C}_{60}$ film. The electrochemistry of $\mathrm{C}_{60}$ in solution has up to six reversible one-electron reduction steps. Solid fullerenes, attached to an electrode via spin coating or drop cast (drop cast usually with toluene) exhibits significantly different electrochemical behavior from that observed when $\mathrm{C}_{60}$ is dissolved in solution. For the electrochemistry of $\mathrm{C}_{60}$ films an electrolyte has to be used. The most common is Acetonitrile $(\mathrm{MeCN})$ and the support electrolyte is $\mathrm{TBAPF}_{6}(0.1 \mathrm{M})$. Early voltammetric studies of $\mathrm{C}_{60}$ films on platinum electrodes in Acetonitrile $(\mathrm{MeCN})$ and ammonium salts such as $\mathrm{TBAPF}_{6}$ reported four reduction peaks with $\mathrm{E}_{1 / 2}$ potentials of $-1.17 \mathrm{~V}, 1.39 \mathrm{~V},-1.88 \mathrm{~V}$ and $-2.24 \mathrm{~V} \mathrm{Vs} \mathrm{Fc} / \mathrm{Fc}^{+}$. The first three peaks closely resemble the first three reduction peaks seen for the solution of $\mathrm{C}_{60}$. However, reported with these $\mathrm{E}_{1 / 2}$ 


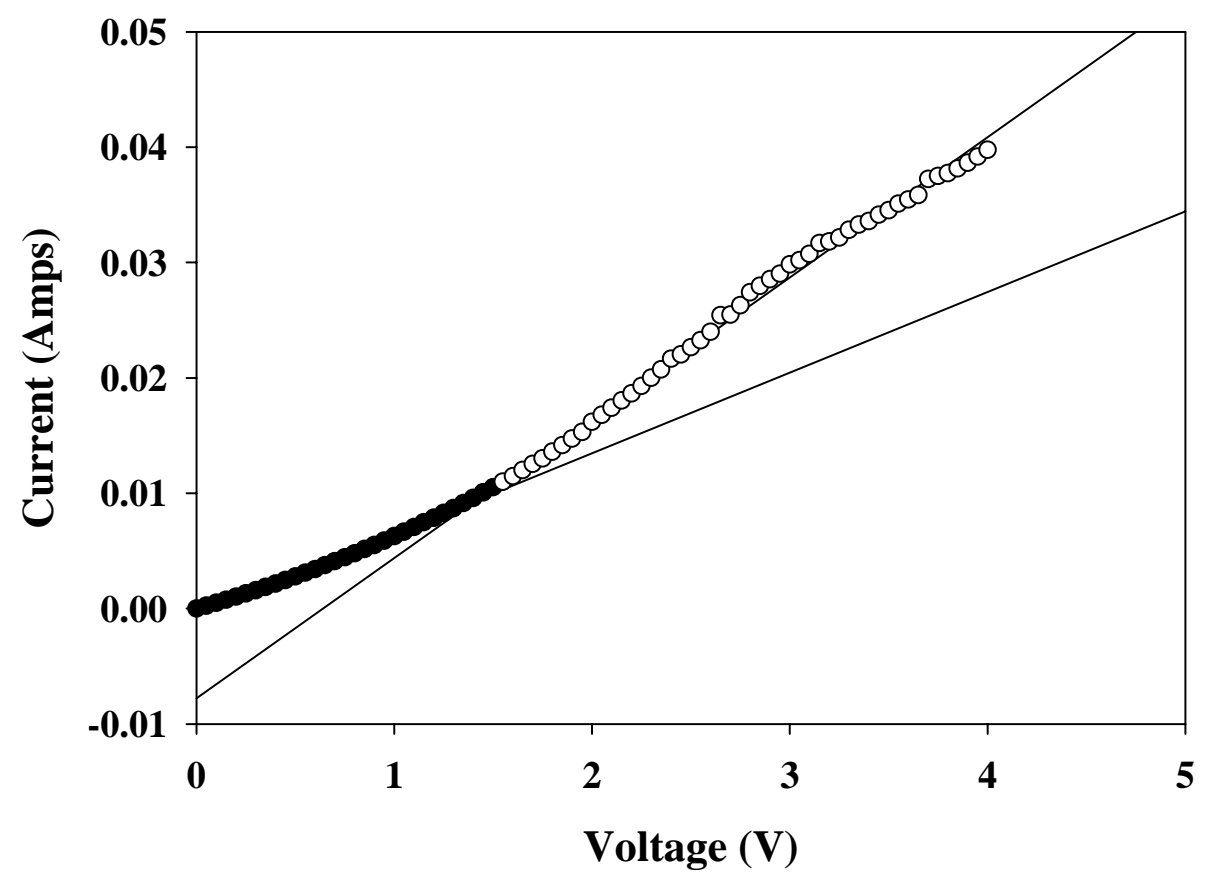

Figure 1 Current-voltage characteristics observed in low voltage region of pristine $\mathrm{C}_{60}$ Film at room temperature

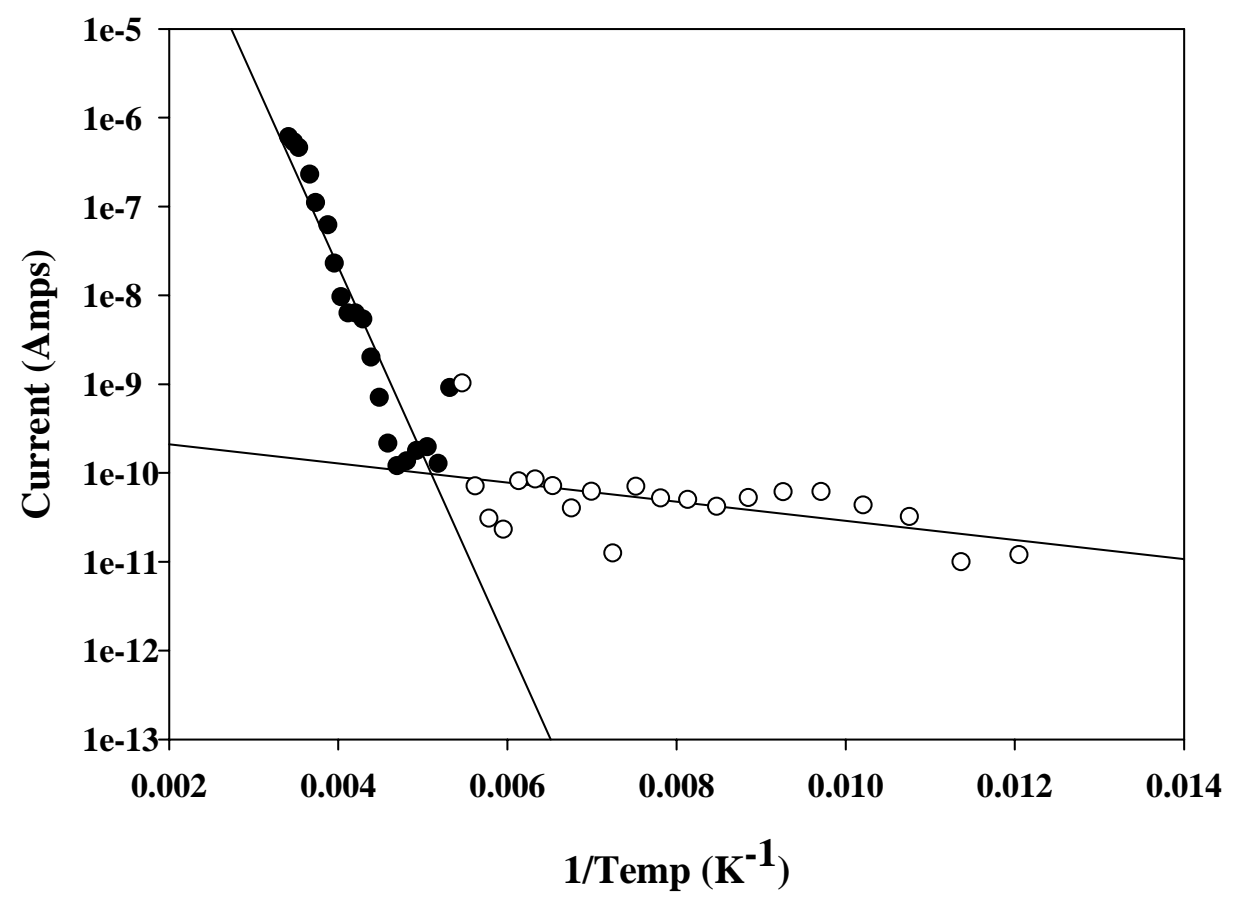

Figure 2: Temperature dependence of low conductivity of Pristine $\mathrm{C}_{60}$ film 
potentials was a large potential splitting between the reduction and the re-oxidation. In the solution the reduction and re-oxidation peaks are reported to occur at approximately the same potential with a peak separation $\Delta \mathrm{E}_{\mathrm{p}}$ of $\sim 59 \mathrm{mV}$. This is characteristic of a single electron transfer as can be deduced from Equation 1 [9].

$$
\Delta E_{p}=E_{p a}-E_{p c}=\frac{0.059}{n} \text { Volts } \quad \text { (Equation 1) }
$$

Thus the peak separation can be used to determine the number of electrons transferred, and it can be seen that one electron process should exhibit a $\Delta \mathrm{E}_{\mathrm{p}}$ of $59 \mathrm{mV}$.

Figure 3 shows a typical cyclic voltammogram obtained for a $\mathrm{C}_{60}$ drop cast film showing the first two reduction peaks. The cyclic voltammogram shows the first reduction peaks for $\mathrm{C}_{60}$ at $-1.17 \mathrm{~V}$ and $-1.39 \mathrm{~V} v \mathrm{vs}$. Fc/Fc ${ }^{+}$and the corresponding re-oxidation peaks at $-0.65 \mathrm{~V}$ and $-0.89 \mathrm{~V}$ vs. $\mathrm{Fc} / \mathrm{Fc}^{+}$. It can also be seen that the peak separation $\Delta \mathrm{E}_{\mathrm{p}}$ for both the reduction and the re-oxidation couples are quite large, i.e. approximately $500 \mathrm{mV}$. The considerable peak separation has been attributed to large structural rearrangements of the film following the first electron transfer $[9,10,11]$. Initially the drop cast should consist of $\mathrm{C}_{60}$ crystallites, each with a fcc packing geometry and a small percentage of toluene, which was trapped in the crystallites during film preparation. Upon reduction, most of the $\mathrm{C}_{60}$ in the film reduces to $\mathrm{C}_{60}{ }^{-1}$. The $\mathrm{TBA}^{+}$counter ion must then diffuse into the lattice in order to balance the negative charges [10]. The counter ion however is comparable in size to the $\mathrm{C}_{60}$ molecule and physically cannot intercalate into the spaces of the fcc structure. Therefore the system rearranges into a new more stable structural configuration, which allows the $\mathrm{TBA}^{+}$ion to balance the changes.

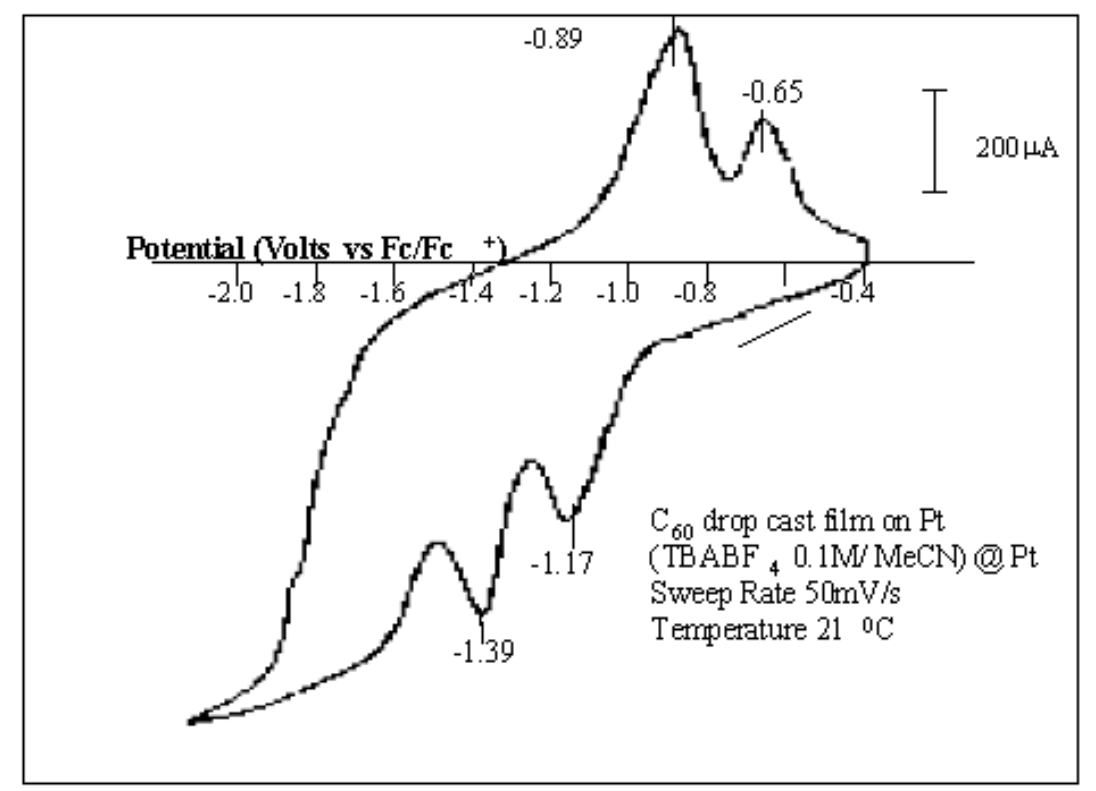

Figure 3: Cyclic Voltammetry of $\mathrm{C}_{60}$ drop cast film

The effect of this proposed rearrangement can be readily observed by in situ Raman spectro-electrochemistry as shown in Figure 4. Initially at $\mathrm{OV}$ the $\mathrm{A}_{2 \mathrm{~g}}$ pentagonal pinch mode is positioned at $1469 \mathrm{~cm}^{-1}$. As the negative potential is applied the pentagonal pinch mode is seen to broaden considerably, and at potentials approaching the first reduction peak $(-1.17 \mathrm{~V})$ a new feature emerges between $1463 \mathrm{~cm}^{-1}$ and $1464 \mathrm{~cm}^{-1}$. The mode positioning of this new feature (initially at $1464 \mathrm{~cm}^{-1}$ ), is reminiscent of the $\sim 6 \mathrm{~cm}^{-1}$ down shift which occurs in $\mathrm{A}_{1} \mathrm{C}_{60}$ [12]. As this emerges at voltages in the region of the first reduction maximum in figure 3 , this mode positioning is attributed to the singly charged $\mathrm{C}_{60}$ within the lattice. In the region of the second $\mathrm{CV}$ peak at $-1.39 \mathrm{~V}$, the Raman profile is seen to further evolve developing a peak at $1459 \mathrm{~cm}^{-1}$. An obvious candidate for this feature is a doubly charged molecule, 
but it does not conform with the generally accepted trend of $6 \mathrm{~cm}^{-1}$ shift per charge, observed in alkali metal fullerene salts. The mode positioning does however match that of the so-called photopolymer [6].
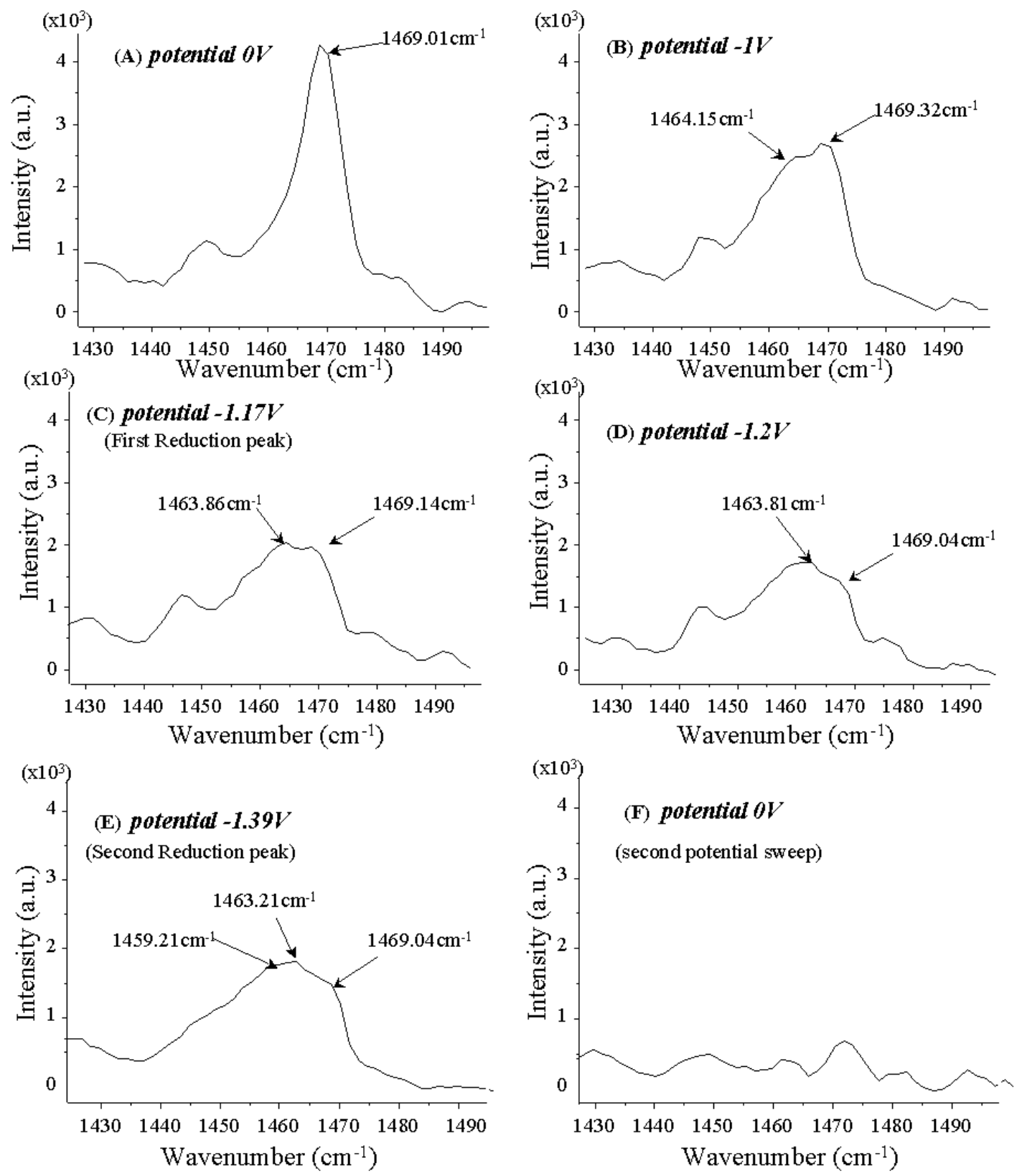

Figure 4: In situ Raman spectra of cyclic voltammetry, A-E first cycle, F is the second

Such a lattice collapse was reported by Smie and Heinze [7], for the electrochemical reduction of $\mathrm{C}_{60}$ films. Solidstate cyclic voltammetery measurements were combined with both in situ conductivity and ESR measurement. In their study they found that the onset of the first reduction peak coincided with a strong increase in conductivity although at the point of maximum reduction, the conductivity values were substantially reduced. This reduction in conductivity was attributed to structural rearrangements due to cationic inclusion into the lattice, and was also 
strongly supported by the peak ESR signal, which corresponded to the peak in the conductivity rather than in the voltammogram. ESR indicates $50 \%$ charging at collapse.

Figure 5 shows conductivity measurements of $\mathrm{C}_{60}$ film at room temperature. It can be seen at low voltages $(<6 \mathrm{~V})$, pristine $\mathrm{C}_{60}$ films show initially the sample to be at most weakly conducting, as discussed above. As the voltage was increased in the positive direction with respect to the aluminum electrode there was a sharp increase in current, at approximately $9.5 \mathrm{~V}$. Further increases in voltage result in little or no change in current until about $10.5 \mathrm{~V}$ whereupon there is a sharp reduction in current observed. As the voltage was increased the characteristics were seen to be irreversible indicating a structural or chemical change in the material. However reversal of the polarity results in similar sharp features, after which the positive bias characteristics can be reproduced.

Figure 5 can be compared with the cyclic voltammetric curve of figure 3 whereby at a well-defined voltage a sharp increase in the conductance results. The relative stability for this highly conducting species may be due to the absence of any charge balancing cation in the sandwich type structure. However further increasing the voltage results in a sharp reduction with a second maximum. The cyclic voltammagram reported by Smie and Heinze also displays a second reduction maximum [7], which was attributed to the formation of dimeric dianions. The presence of a second maximum in Figure 5 may thus suggest that the $\mathrm{C}_{60}$ lattice is unstable to the addition of electrons and can collapse to a polymeric-like species with or without the presence of charge balancing cations.

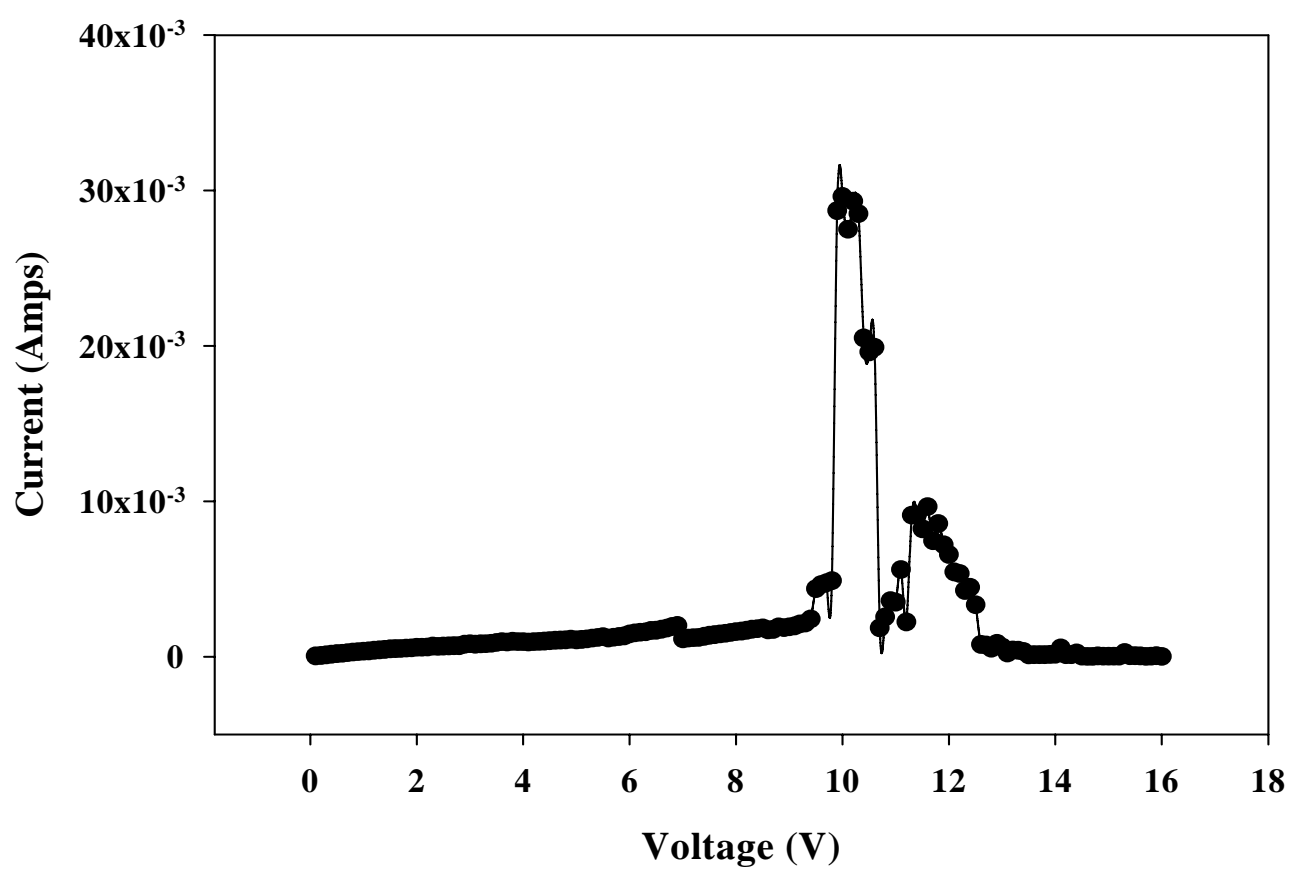

Figure5. Current-Voltage characteristics observed for Pristine $\mathrm{ITO} / \mathrm{C}_{60} / \mathrm{Al}$ structure at $300 \mathrm{~K}$

In situ with Raman spectroscopy was performed on the $\mathrm{C}_{60}$ sandwich structures at room temperature. At low voltages, as shown in figure 6 , the profile has maximum at $1469 \mathrm{~cm}^{-1}$, characteristic of pristine $\mathrm{C}_{60}$. At 12 volts, after the proposed collapse of the $\mathrm{C}_{60}$ lattice, the profile has changed to that characteristic of a polymerized $\mathrm{C}_{60}$ lattice. When the voltage is removed, this profile remains, indicating that is not characteristic of a charged species but rather of a modified $\mathrm{C}_{60}$ lattice.

Optically, the polymerisation of $\mathrm{C}_{60}$ is well documented. Of note, the process only occurs above the orientational phase transition where the rotational freedom allows adjacent molecules to align to optimum reaction conditions. 


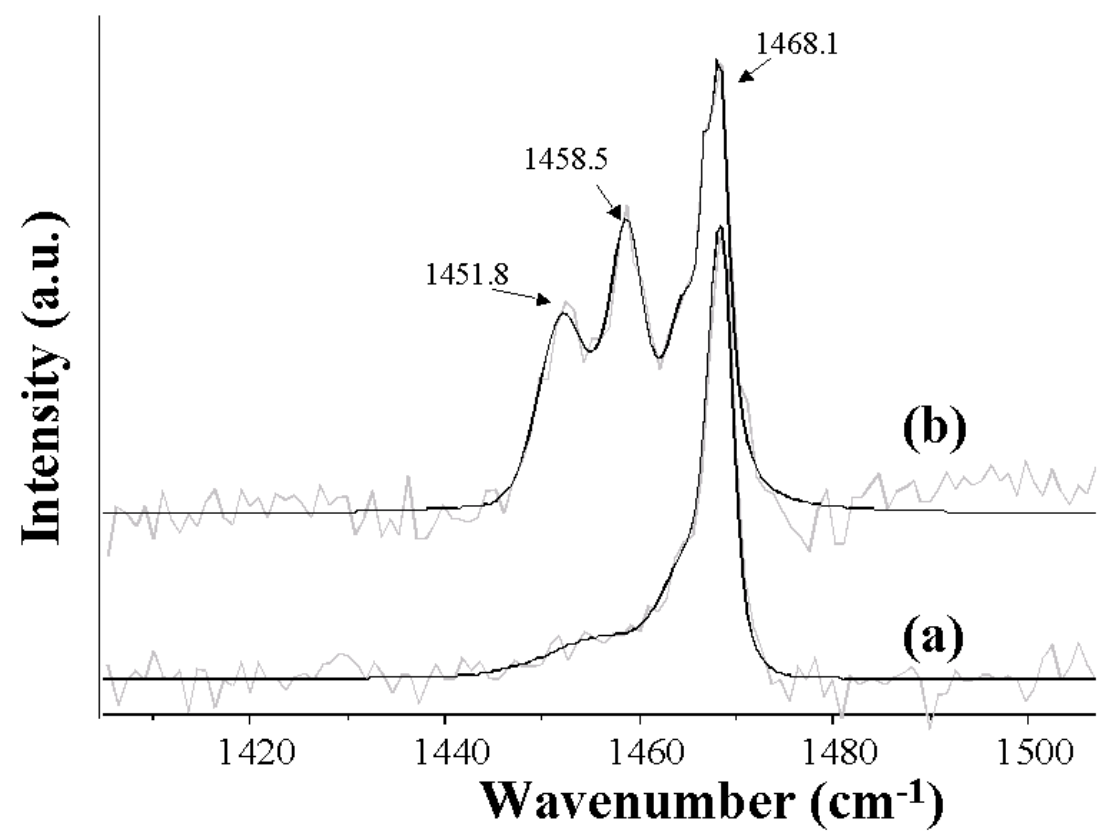

Figure 6: Raman Spectra of $\mathrm{C}_{60}$ film showing the pentagonal pinch mode at $1469 \mathrm{~cm}^{-1}$ and after breakdown of the excited state showing two new peaks at $1458 \mathrm{~cm}^{-1}$ and $1452 \mathrm{~cm}^{-1}$. The Raman signature returns to the $1469 \mathrm{~cm}^{-1}$ position after electroluminescence

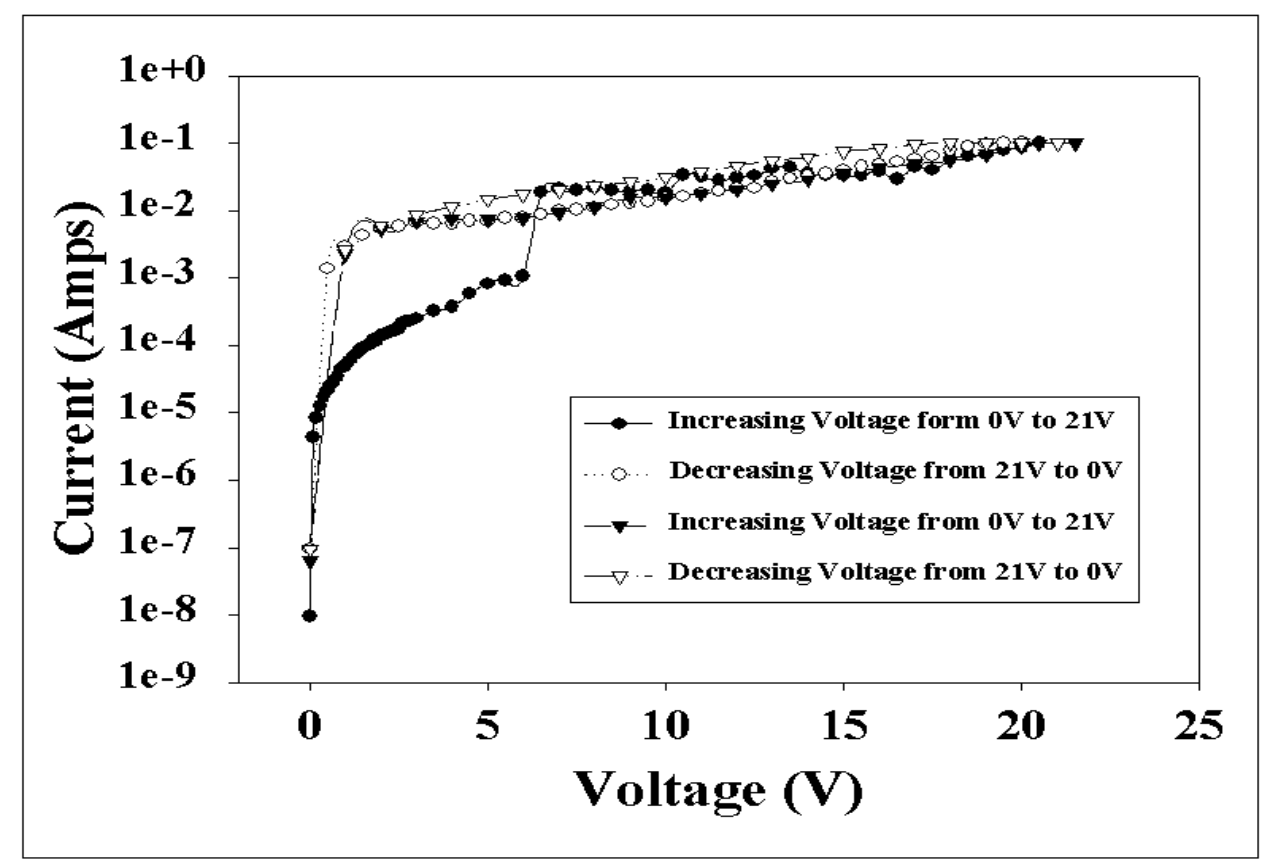

Figure 7: Current voltage characteristics observed for ITO/ $\mathrm{C}_{60} / \mathrm{Al}$ sandwich structure at $30 \mathrm{~K}$

Below this phase transition the material is photochemically stable. Figure 7 shows IV characteristics of the $\mathrm{C}_{60}$ sandwich structure at $20 \mathrm{~K}$. As in the room temperature measurements, a dramatic increase in the conductance of the 
structure is observable at an apparent threshold voltage. At low temperatures, however, this high conducting state is stable with respect to further increase in voltage. The characteristics are fully reversible and cyclable. These results lend strength to the proposal that the $\mathrm{C}_{60}$ solid state can be effectively doped to a conducting state by the electrical injection of charges.

\section{CONCLUSION AND DISCUSSION}

For the first part of this paper involving the conductivity, it can be suggested that a highly conducting $\mathrm{C}_{60}$ film can be readily produced by application of a moderate. Further to this it is speculated that the conducting species maybe analogous to a high intensity optically excited state specific to solid-state $\mathrm{C}_{60}$. The possibility of producing such an excited state at relatively low voltages would contribute greatly to then development of potential fullerene based devices in the near future.

Cyclic voltammetry of $\mathrm{C}_{60}$ films results in two reduction peaks and two re-oxidation peaks. These peaks may to shift to a different voltage depending on the electrode being used and on the set up of the apparatus. When the cyclic voltammetry was used in situ with resonant Raman a mode positioning at $1463.86 \mathrm{~cm}^{-1}$ for the first reduction peak at $1.17 \mathrm{eV}$ was found, in good agreement with previously reported resonant Raman measurements of anionic $\mathrm{C}_{60}$, which is, characterised the mono-anionic signature as a shift of $6 \mathrm{~cm}^{-1}$ from the pentagonal pinch mode at $1469 \mathrm{~cm}^{-1}$. These shifts are similar to those observed by Kuzmany for doped $\mathrm{C}_{60}$ films [12]. The mechanism for the second reduction peak in figure 5 should be similar to that of the first reduction, however the reduction occurs in a film whose electronic configuration is significantly different to the pristine fcc structure. For this reason it has been suggested that further processes can take place in addition to the electron transfer and incorporation of counter ions. It has been proposed by [5] analogy to similar findings with electron-attracting aromatics and conjugated chain like oligimers, that after the generation of $\mathrm{C}_{60}{ }^{-1}$, dimeric dianions are immediately formed i.e. $\left(\mathrm{C}_{60}{ }^{-1}\right)_{2}$. Figure 4 shows a further softening of the pentagonal pinch mode towards the lower Raman frequency of $1460 \mathrm{~cm}^{-1}$ as the second reduction maximum is reached. The softening of this mode is indicative of increased intermolecular interactions between the $\pi$-electrons, which is consistent with the suggestion that this reduction peak is due to the production of dimeric dianions $\left(\mathrm{C}_{60}{ }^{-1}\right)_{2}$. In situ ESR and conductivity measurements by Smie and Heinz seem to further support this concept [4]. Moreover the conductivity measurements revealed that neither the electrochemically doped films (which are essentially doped with the counter ion, $\mathrm{C}_{60}{ }^{-} \mathrm{TBA}^{+}$) nor the 'dimeric' films are conductive i.e. before the peak maximum for the first reduction in figure 5. In situ Raman measurements of the sandwich structures correlate with these observations, indicating that the $\mathrm{C}_{60}$ lattice is unstable to charge injection. At low temperatures, however, the system is seen to be stable and a high conductivity state may be induced at relatively low voltages. The results presented here highlight the importance of the characterization of the charged species in understanding the transport processes. While they do confirm that a high conductivity state can be generated in fullerene films, the importance of lattice stabilization is highlighted.

\section{ACKNOWLEDGEMENTS}

The Focas Institute was funded under the Irish government NDP 2000 - 2006 with assistance from European Regional Development Fund. The work was also carried out with help from the DIT Seed Fund and Enterprise Ireland.

\section{REFERENCES}

1. H.W Kroto, J.R Heath, S.C O’Brien, R.F. Curl, and R.E. Smalley, Nature 318,162, (1985).

2. Handbook of Organic Conductive Molecules and Polymers. Volume 1 Charge transfer salts, Fullerenes and Photocinductors. Edited by H.S. Nalwa 1997, John Wiley and Sons Inc.

3. H.J. Byrne, W.K. Maser, M. Kaiser, W.W. Rühle, L. Akselrod, A.T. Werner, J. Anders, X.-Q. Zhou, G.Mahler, T. Kuhn, A. Mittelbach and S. Roth, Appl. Phys. A, 57, 303 (1993)

4. J. H. Schoen, Ch Kloc, B. Batlogg, Nature 408, 549 (2000)

5. www.nd.edu/ jbarkai/schonquestions. 
6. H.J. Byrne, in Physics and Chemistry of Fullerenes and Derivatives, H. Kuzmany, J. Fink, M. Mehring and S. Roth eds., World Scientific Signapore, p183(1995)

7. A. Smie and J. Heinze, Physics and Chemistry of Fullerenes and Derivatives, World Scientific Singapore (1995)

8. M. Kaiser, W.K. Maser, H.J. Byrne, A. Mittelbach and S. Roth, Solid State Commun., 87, 281 (1993)

9. A.J. Bard, L.R. Faulkner. 'Electrochemical methods, fundamentals and applications' John Wiley and Sons Inc. (1980)

10. C. Johoulet. A.J. Bard, F. Wudl, Am. Chem Soc 113, 5456, (1991).

11. C. Johoulet. Y.S. ObengY-Tkim, F.Zhou A.J. Bard, J Am. Chem. Soc 114, 4237, (1997).

12. Kuzmany, M. Matus, T. Pichler and J. Winter, in Physics and Chemistry of Fullerenes, K. Prassides ed., Klewer Academic, Dordrecht(1994).

*j_moghal@hotmail.com; phone 01402 7929; fax 014027901 